\title{
Daunorubicin in acute leukaemia
}

\author{
R. L. Souhami \\ M.B., B.Sc., M.R.C.P. \\ Medical Registrar, \\ Department of Haematology
}

\author{
T. A. J. Prankerd \\ M.D., F.R.C.P.
}

Professor of Clinical Haematology

\begin{abstract}
Department of Haematology, University College Hospital, London, W.C.1
\end{abstract}

\section{/}

Daunorubicin has been used in the treatment of six cases of acute lymphoblastic and thirteen cases of acute myeloblastic and mono-myeloblastic leukaemia.

Complete remissions were obtained in eight patients, three with acute lymphoblastic leukaemia and five with acute myeloblastic leukaemia.

Marrow aplasia makes the drug difficult to administer, but no patients died from this cause, in this series.

In some patients good remissions were obtained with relatively low doses of daunorubicin after preliminary treatment with 6-mercaptopurine.

\section{Introduction}

Daunorubicin, an antibiotic derived from a strain of Streptomyces coeruleorubidus, has been used in the treatment of acute leukaemia, alone and in combination with other drugs. The results obtained in the production of an initial remission have been encouraging (Mathé et al., 1967; Bernard et al., 1967; Boiron et al., 1969). Since June 1967 we have treated all of our new patients with acute leukaemia with daunorubicin, and also some patients in relapse from previously treated disease. This report describes our experience in the use of this drug, usually in combination with other anti-leukaemic drugs, in nineteen patients.

\section{Patients}

Details of the patients and their treatment are seen in Table 1. Eleven adults aged 25-63 and one child aged 14, were diagnosed as having acute myeloblastic leukaemia. One patient (No. 9) had acute monocytic leukaemia. Three adults aged 16-75 and three children aged 6-15, had acute lymphoblastic leukaemia.

Requests for reprints should be addressed to: Dr Prankerd, Department of Haematology, University College Hospital, London, W.C.1.
Most patients were being treated for the first time, but five had had partial or complete remissions prior to treatment.

\section{Treatment}

Daunorubicin was given in an intravenous, fastrunning infusion, care being taken to avoid extravasation. Recently, during the periods of infusion and for $30 \mathrm{~min}$ afterwards, a tight band has been used to occlude the arterial circulation to the scalp. Since adopting this procedure, none of our patients has developed alopecia which could be attributed to daunorubicin.

The initial injection was usually $1.5 \mathrm{mg} / \mathrm{kg}$, although during the early use of the drug both smaller and larger doses have been given. The effect on the peripheral white count was observed each day, but bone marrow examinations were not made during the period of active treatment. The effect of the injection was to cause a rapid fall in total count, primarily due to a great fall in the numbers of blast cells and immature cells. Neutropenia, lymphopenia and thrombocytopenia also occur, and the maximum effect was usually attained at the 3 rd to the 7 th day. At this time a further injection was given if the blast cell count was no longer falling. Many patients were neutropenic before treatment was started, and in these patients continuing neutropenia was not a bar to a further dose. If the patient became neutropenic $\left(<1000 / \mathrm{mm}^{3}\right)$ as a result of the injection, then a further injection was not given provided the blast count had fallen to low levels (less than $10-15 \%$ of the count). In this event, repeated white blood counts were performed, and if the blast cell count began to rise progressively, a further injection was given at a similar dose. Two patients who had become neutropenic as their blast cell count had fallen, did not need a further injection, since the blast cell count continued to fall slowly. Subsequently the neutrophil count rose and complete remission was obtained. 
TABLE 1

\begin{tabular}{|c|c|c|c|c|c|c|c|c|c|}
\hline \multirow{2}{*}{ No. } & \multirow{2}{*}{ Age } & \multirow{2}{*}{ Sex } & \multirow{2}{*}{ Diagnosis } & \multirow{2}{*}{$\begin{array}{l}\text { Previous } \\
\text { drugs }\end{array}$} & \multirow{2}{*}{$\begin{array}{l}\text { Previous } \\
\text { remissions }\end{array}$} & \multicolumn{2}{|c|}{ Daunorubicin } & \multirow{2}{*}{$\begin{array}{l}\text { Other } \\
\text { drugs }\end{array}$} & \multirow{2}{*}{ Result } \\
\hline & & & & & & Total mg & $\mathrm{mg} / \mathrm{kg}$ & & \\
\hline 1 & 15 & $\mathrm{~F}$ & ALL & - & - & 75 & $1 \cdot 75$ & 6MP.P. & R. 2 months + \\
\hline 2 & 75 & $\mathrm{M}$ & ALL & - & - & 120 & 2 & 6MP. & R. 8 months + \\
\hline 3 & 6 & F & ALL & 一 & - & 21 & 1 & 6MP.P. & R. 1 month + \\
\hline 4 & 19 & $\mathbf{M}$ & ALL & $\mathbf{P}$ & Partial remission & 500 & 9 & 6MP.P. & P.R. 1 month \\
\hline 5 & 58 & $\mathbf{M}$ & ALL & $\mathbf{P}$ & Partial remission & 380 & 6 & P. & P.R. 2 months \\
\hline 6 & 8 & $\mathrm{~F}$ & ALL & $\mathbf{P}$ & Partial remission & 105 & 5 & P. & Died 5 weeks \\
\hline 7 & 16 & $\mathrm{~F}$ & AML & $\mathbf{P}$ & Third relapse & 175 & 4 & 6MP.P. & Died 3 weeks \\
\hline 8 & 32 & $F$ & AML & - & - & 220 & 5 & 6MP.Me & R. 1 year + \\
\hline 9 & 45 & $\mathbf{F}$ & A.Mono.L. & - & - & 130 & 3 & 6MP.P. & R. 1 year + \\
\hline 10 & 60 & $\mathrm{~F}$ & AML & - & 一 & 75 & $1 \cdot 5$ & 6MP.P. & R. 18 months \\
\hline 11 & 79 & F & AML & - & - & 560 & $9 \cdot 3$ & 6MP. & R. 1 year + \\
\hline 12 & 42 & $\mathbf{F}$ & AML & - & - & 200 & $3 \cdot 5$ & 6MP.P. & R. 6 months \\
\hline 13 & 14 & $\mathbf{F}$ & AML & - & - & 220 & 6 & V.P. & P.R. 4 months \\
\hline 14 & 25 & $F$ & AML & - & - & 320 & 5 & ECI.P. & P.R. 3 months \\
\hline 15 & 54 & M & AML & 一 & - & 200 & 4 & - & Died 3 weeks \\
\hline 16 & 63 & $\mathbf{M}$ & AML & - & - & 100 & 2 & - & Died 2 weeks \\
\hline 17 & 54 & $\mathbf{F}$ & AML & 一 & - & 600 & 10 & 6MP.P. & Died 2 months \\
\hline 18 & 42 & $\mathbf{M}$ & AML & - & - & 200 & 3 & & Died 3 weeks \\
\hline 19 & 56 & $\mathbf{M}$ & $\mathrm{AM}-\mathrm{ML}$ & 6MP.Cyc. & Partial remission & 275 & 4 & V.P. Act. D. & Died 3 weeks \\
\hline
\end{tabular}

ALL, acute lymphoblastic leukaemia; AML, acute myeloblastic leukaemia; A.Mono.L., acute monocytic leukaemia; AM-ML, acute mono-myelocytic leukaemia; 6MP, 6-mercaptopurine; P, prednisone; V, vincristine; ECI, extracorporeal irradiation; Act.D., actinomycin D; Cyc., cyclophosphamide; R, remission; PR, partial remission.

Injections were repeated according to the indications mentioned above, but if the effect of repeated treatment was only to produce a mixture of aplasia and incompletely treated leukaemia, the drug was discontinued. This situation is not infrequent (Boiron et al., 1969).

When the neutrophil count was below $1500 / \mathrm{mm}^{3}$, the patient was placed in a side ward with reversed barrier nursing. In the last year all of these patients have been placed on sulphamethoxazole and trimethoprim (Septrin) two tablets twice daily. Fresh blood was transfused as required.

Most patients received prednisone and 6-mercaptopurine (6-MP) during the initial treatment with daunorubicin. Details are given in Table 1. Maintenance treatment was usually with 6-MP and prednisone. After the treatment with daunorubicin, in those patients with haematological remission, the marrow examination was repeated. Patients with a normal blood count, no clinical evidence of disease and less than $5 \%$ blast cells in their bone marrow were regarded as having complete remissions; in others with a greater number of blast cells in their marrows or with an abnormal peripheral blood count the remission has been classified as partial.

\section{Results}

Of the twelve patients with acute myeloblastic and monocytic leukaemia, five had a remission of their disease. At the time of writing four of them have had remissions lasting for more than 1 year. One of these patients has relapsed after a remission of 18 months' duration. Two patients have had partial remissions and six have died without clinical improvement.

Of the seven patients with acute lymphoblastic leukaemia there were complete remissions in three, two patients had partial remissions and two died.

All of the patients who died had widespread disease at the time of death and in only one case might the treatment have contributed to the outcome. This patient developed a chest infection the day after daunorubicin was given and he died during the early phase of aplasia. Three patients (Nos. 19, 15 and 14) were gravely ill at the time treatment was undertaken and died within 3 weeks; two others (Nos. 6 and 7) had relapsed after previous treatment and had very advanced disease before treatment with daunorubicin was begun.

Several patients who went into remission were remarkably sensitive to the drug and only very small doses were needed. Such an example is Case 10.

A 60-year-old woman with a 3-month history of oral ulceration and malaise. On admission she was anaemic but had no other abnormalities. Hb 7.39 $\mathrm{g} / 100 \mathrm{ml}$; WBC $3100 / \mathrm{mm}^{3}$ (neutrophils $55 \%$, lymphocytes $30 \%$, blast cells $8 \%$, monocytes $5 \%$ ). Platelets $450,000 / \mathrm{mm}^{3}$. Marrow: heavy infiltration 
with blast cells. Leucocyte alkaline phosphatase greatly reduced.

After 1 week of 6-MP (Fig. 1), two injections of

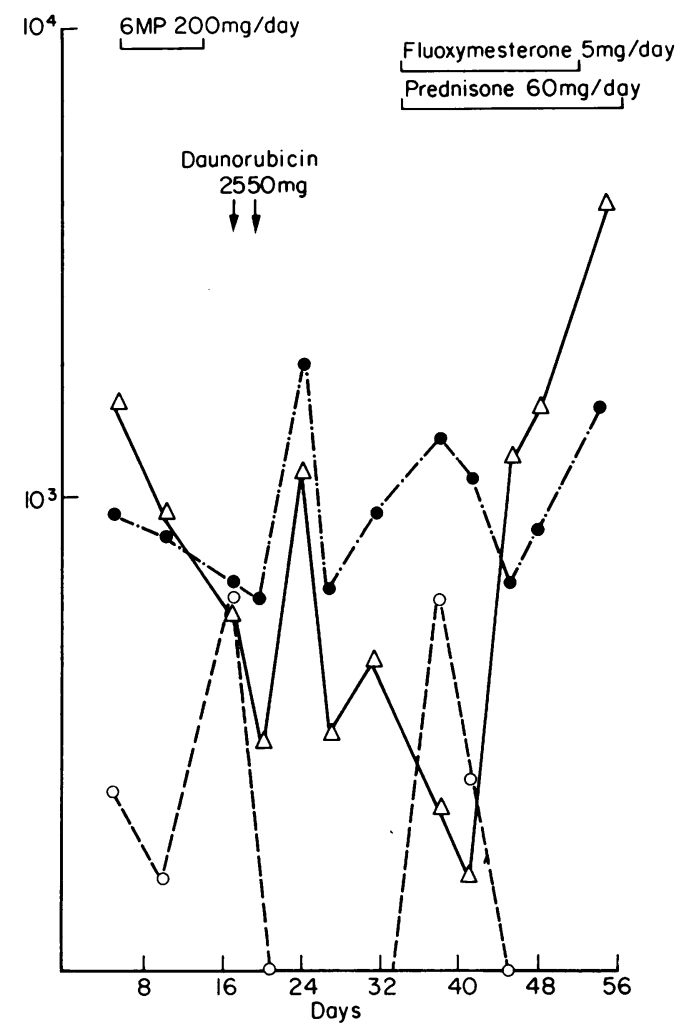

FIG. 1. Acute myeloblastic leukaemia. Response to daunorubicin. Patient No. 10. O, Blasts and immature cells; $\triangle$, polymorphs; $\bigcirc$, lymphocytes.

daunorubicin were given to a total of $75 \mathrm{mg}(1 \cdot 5$ $\mathrm{mg} / \mathrm{kg}$ ). This small dose was given at a time when experience with the drug was limited. There was a rapid fall in total $\mathrm{WBC}$ to $1000 / \mathrm{mm}^{3}$. 1 week later there was a temporary reappearance of immature cells. On starting prednisone the white count rose and there was complete remission in the blood and bone marrow which was maintained for 18 months.

None of our patients had severe or prolonged aplasia, and none developed septicaemia during treatment, but three very ill patients who had infections before treatment was started proved extremely difficult to treat.

Toxicity to cardiac muscle is a well recognized complication of the drug (Malpas \& Bodley Scott, 1968), and is more frequent with higher doses. In this series, with lower doses of daunorubicin, it has not been encountered. However, one patient aged
16 , died suddenly after daunorubicin $(4 \mathrm{mg} / \mathrm{kg})$, but she had severe generalized haemorrhagic varicella at the time, and the cause of death was thought to be a viral myocarditis.

\section{Discussion}

Initial reports of the use of daunorubicin in acute lymphoblastic leukaemia have been encouraging (Jacquillat et al., 1967; Mathé et al., 1967; Bernard et al., 1967; Dreyfus et al., 1968; Boiron et al., 1969). Of thirty-six cases, many of who were resistant to most other drugs, complete remissions were obtained in twenty-one (Bernard et al., 1967). In conjunction with prednisone and vincristine, complete remission was achieved in all of eleven previously untreated children with acute lymphoblastic leukaemia (Mathé et al., 1967). In acute myeloblastic leukaemia, the reported rates of remission have been equally encouraging particularly since the remission rate in adults with the disease using other drugs is so low (Medical Research Council Report, 1963). In the series of Boiron et al. (1969) daunorubicin produced complete remissions in twenty out of thirty-six adults in their first attack, and in six out of seven children. The drug appeared less effective in treatment of relapses (nine complete remissions out of twenty-one cases). The same workers (Dreyfus et al., 1968) have previously reported remissions in eleven out of nineteen cases, of whom sixteen had had no previous treatment. However, Malpas \& Bodley Scott (1968) reported only three complete remissions out of nineteen cases of acute myeloblastic and monocytic leukaemia and of the nine previously untreated cases only one complete remission was obtained.

Of the nineteen cases described here, six had acute lymphoblastic leukaemia, and complete remission was obtained in all of the patients presenting for the first time, but in none of the previously treated patients. Of the thirteen patients with acute myeloblastic or acute mono-myelocytic leukaemia, complete remissions were obtained in five, and partial remissions in two. All of the patients who achieved remission were previously untreated.

It has been pointed out (Mathé et al., 1967) that the duration of remission obtained with daunorubicin is sometimes striking. In four of the five cases of acute myeloblastic and monocytic leukaemia who were successfully treated, the remission has lasted for more than a year.

The drug has been used here in combination with other anti-leukaemic agents particularly 6-MP and prednisone, and these other drugs may have played a part in the production of remissions. However, in all the cases who have remitted the remission followed immediately after the use of daunorubicin (as is illustrated in the case report). Nevertheless, it is our 
impression that the combination of 6-MP and daunorubicin may be particularly effective and possibly allow a smaller dose of daunorubicin to be administered.

The drawbacks to the use of daunorubicin lie in the toxic effects. The most serious of these are bone marrow aplasia and cardiotoxicity. The effect on the heart is manifested initially by ST and $T$ wave changes (Malpas \& Bodley Scott, 1968) and subsequently by sudden intractable heart failure. This complication is usually found with large doses of the drug, but cardiographic abnormalities may appear early in treatment. We have not taken electrocardiograms regularly during treatment, but only one of our patients had any illness suggestive of heart failure, and she had a severe viral illness at the time.

The main toxic effect is marrow depression which may progress to a period of marrow aplasia lasting from a few days to several weeks. If the aplasia is prolonged for more than 1 or 2 weeks, septicaemia, particularly with Gram-negative organisms, often occurs. In one series (Bernard et al., 1967) there were nineteen fatal aplasias our of sixty-one patients. The response of any individual patient is difficult to predict, but severe aplasia seems to occur more commonly in patients who have been given daunorubicin when protracted treatment with other drugs has failed, and also in those who are given large doses of the drug in order to eliminate persistent blast cells from the blood or marrow. The mean dose administered to our patients was 4.4 $\mathrm{mg} / \mathrm{kg}$, which is much lower than in some other series. None of our patients developed severe aplasia, and there were no fatalities from this cause. When the neutrophil count fell below $1500 / \mathrm{mm}^{3}$ all patients received sulphamethoxazole and trimethoprim (Septrin) and none developed septicaemia.

The problem of giving the correct dose is made more difficult by the fact that some patients have a remission of their disease at very low dosage. Five out of eight of the patients who had a remission were given $3 \mathrm{mg} / \mathrm{kg}$ or less. This may be in part due to the fact that 6-MP and prednisone were given at the same time, in some cases.

Although further experience with the drug is still needed, it may be advisable to err on the side of giving too little and risk not achieving a complete remission in one or two patients, in order to avoid the great risk of fatal aplasia and cardiotoxicity which occurs with protracted treatment and with large doses of the drug. In addition it would also seem unwise to use the drug except as a last resort if the patient has had recent intensive and unsuccessful treatment with other anti-leukaemic agents.

The results so far obtained with daunorubicin indicate that it may be the most effective means of inducing an initial remission in acute myeloid leukaemia either alone or in combination with other drugs, and that it is also highly effective in producing remission in acute lymphoblastic leukaemia.

\section{References}

Bernard, J., Jacquillat, C., Boiron, M., Najean, Y., SeligmanN, M., Tanzer, J., Weil, M. \& Lortholary, P. (1967) Trial of treatment of acute lymphoblastic and myeloblastic leukaemia by a new antibiotic (Rubidomycin). Presse Médicale, 75, 951.

Boiron, M., Jacquillat, C., Weil, M., TANzer, J., LeVy, D., Sultan, C. \& Bernard, J. (1969) Daunorubicin in the treatment of acute myelocytic leukaemia. Lancet, $\mathbf{i}, 330$.

Dreyfus, B., Sultan, C., Boiron, M., Jacquillat, C., WeIL, M. \& Rochanit, H. (1698) Notes on the induction treatment by rubidomycin of 19 cases of acute myeloblastic leukaemia. Presse Médicale, 76, 55.

Jacquillat, C., TANzer, J., Boiron, M., Najean, Y., Weil, M. \& Bernard, J. (1967) Rubidomycin. A new agent active in the treatment of acute lymphoblastic leukaemia. Lancet, ii, 27.

MAlPas, J.S. \& Bodley ScotT, R. (1968) Rubidomycin in acute leukaemia in adults. British Medical Journal, 3, 227.

Mathé, G., Hayat, M., Schwarzenberg, L., Amiel, J.L., Schneider, M., Cattan, A., Schlumberger, J.R. \& JASMIN, C. (1967) Acute lymphoblastic leukaemia treated with a combination of prednisone, vincristine and rubidomycin. Lancet, ii, 380.

Medical Research Council Report (1963) Treatment of acute leukaemia in adults. British Medical Journal, 1, 7. 